\title{
OCORRÊNCIA DE BACTÉRIAS DIAZOTRÓFICAS E FUNGOS MICORRÍZICOS ARBUSCULARES NA CULTURA DA MANDIOCA ${ }^{1}$
}

\author{
ELCIO LIBORIO BALOTA ${ }^{2}$, ELI SIDNEY LOPES ${ }^{3}$, MARIANGELA HUNGRIA ${ }^{4}$ e JOHANNA DÖBEREINER ${ }^{5}$
}

RESUMO - Este trabalho teve como objetivo avaliar a ocorrência, isolar e identificar fungos micorrízicos arbusculares associados à cultura da mandioca (Manihot esculenta). Amostras de solo rizosférico e de várias partes da planta (raízes, tubérculos, manivas e folhas) de locais nos Estados do Rio de Janeiro, São Paulo e Paraná, foram inoculadas nos meios LGI-P, NFb-malato e NFb-GOC, avaliando-se o número mais provável de células e a atividade de redução de acetileno. Bactérias diazotróficas foram isoladas de todas as partes da planta, com exceção das folhas, sendo identificadas como Klebsiella sp., Azospirillum lipoferum e uma bactéria denominada "E", provavelmente pertencente ao gênero Burkholderia. A Bactéria E acumulou de 7,63 mg a 14,84 mg de N/g de C em meio semi-sólido, isento de N, e conseguiu manter a capacidade de fixação biológica de $\mathrm{N}$, mesmo após uma dezena de repicagens consecutivas. A colonização micorrízica variou de $31 \%$ a $69 \%$, e a densidade de esporos de 10 a 384 esporos $/ 100 \mathrm{~mL}$ de solo, predominando as espécies Entrophospora colombiana e Acaulospora scrobiculata no Rio de Janeiro, A. scrobiculata e Scutellospora heterogama no Paraná e em Piracicaba (São Paulo) e A. appendicula e S. pellucida em Campinas (São Paulo).

Termos para indexação: Azospirillum, Burkholderia, ecologia microbiana, fixação de $\mathrm{N}_{2}$, Klebsiella, Manihot esculenta.

\section{OCCURRENCE OF DIAZOTROPHIC BACTERIA AND ARBUSCULAR MYCORRHIZAL FUNGI ON THE CASSAVA CROP}

\begin{abstract}
This study was performed to evaluate the occurrence and to isolate and identify diazotrophic bacteria and arbuscular mycorrhizal fungi associated with the cassava (Manihot esculenta) crop. Samples from rhizospherical soil, roots, tubers, stems and leaves from several localities of the States of Rio de Janeiro, São Paulo and Paraná, in Brazil, were inoculated in three media specific for diazotrophic associative bacteria, LGI-P, NFb-malate and NFb-GOC, evaluating the most probable number of cells and the acetylene-reducing activity. Diazotrophic bacteria were detected in all plant parts except for the leaves, and were identified as Klebsiella sp., Azospirillum lipoferum and a bacterium called "E", probably belonging to the Burkholderia genus. Bacterium $\mathrm{E}$ was able to accumulate, in the N-free semi-solid media, from 7.63 to $14.84 \mathrm{mg}$ of N/g of C and to maintain $\mathrm{N}$ fixation capacity after ten consecutive transferences. Mycorrhizal root colonization varied from $31 \%$ to $69 \%$ and spore density from 10 to 384 spores $/ 100 \mathrm{~mL}$ of soil, predominating the species Entrophospora colombiana and Acaulospora scrobiculata in Rio de Janeiro, A. scrobiculata and Scutellospora heterogama in Paraná and in Piracicaba (São Paulo), and A. appendicula and S. pellucida in Campinas (São Paulo).
\end{abstract}

Index terms: Azospirillum, Burkholderia, microbial ecology, $\mathrm{N}_{2}$ fixation, Klebsiella, Manihot esculenta.

${ }^{1}$ Aceito para publicação em 21 de julho de 1998.

Extraído da tese de doutorado do primeiro autor apresentada à Universidade Federal Rural do Rio de Janeiro.

${ }^{2}$ Biólogo, Ph.D., Instituto Agronômico do Paraná (IAPAR), Caixa Postal 481, CEP 86001-970 Londrina, PR. Bolsista do CNPq. E-mail: elbalota@sercomtel.com.br

${ }^{3}$ Eng. Agr., Ph.D., Instituto Agronômico de Campinas, Caixa Postal 28, CEP 13001-970 Campinas, SP. Bolsista do CNPq

${ }^{4}$ Eng $\underline{a}$ Agra, Ph.D., Embrapa-Centro Nacional de Pesquisa de Soja (CNPSo), Caixa Postal 231, CEP 86001-970 Londrina, PR. Bolsista do CNPq.

\section{INTRODUÇÃO}

A cultura da mandioca possui grande adaptabilidade às condições de clima e fertilidade do solo, mesmo apresentando alto requerimento de nu-

\footnotetext{
${ }^{5}$ Eng $\underline{a}$ Agr ${ }^{\mathrm{a}}$, Ph.D., Embrapa-Centro Nacional de Pesquisa de Agrobiologia (CNPAB), Caixa Postal 74505, CEP 23851-970 Seropédica, RJ. Bolsista do CNPq.
} 
trientes e sendo considerada esgotadora de solos (Cock \& Howeler, 1978; Howeler, 1981a, 1981b), embora seja tradicionalmente cultivada sem a aplicação de fertilizantes (Howeler, 1981a). Essa cultura não responde, de maneira consistente, à adubação, mesmo em solos com baixa disponibilidade de nutrientes (Gomes, 1987). Este paradoxo tem sido relacionado às associações das raízes com fungos micorrízicos arbusculares (MA) (Howeler, 1981a, 1981b; Howeler et al., 1987), e pode estar também relacionado à ocorrência de bactérias diazotróficas ou promotoras do crescimento de plantas (Balota, 1994).

A cultura da mandioca tem sido considerada como uma das mais dependentes da associação micorrízica. Em condições naturais, observa-se um grande número de espécies de fungos MA associados à cultura, mas apenas algumas têm-se mostrado eficientes (Howeler et al., 1987). Segundo Sieverding (1991), avaliações em áreas com mandioca em Mondomo, na Colômbia, evidenciaram até 2.800 esporos por $100 \mathrm{~g}$ de solo, e 12 espécies, sendo predominantes Acaulospora sp., Entrophospora colombiana, Glomus fasciculatum e A. appendicula. Por outro lado, Dodd et al. (1990), também em solos ácidos na Colômbia, encontraram em torno de 100 esporos por $100 \mathrm{~g}$ de solo, com predominância de G. occultum, A. myriocarpa, E. colombiana, A. mellea, A. morrowae e G. fasciculatum. Deste modo, é importante conhecer as espécies de fungos MA associadas à cultura, bem como seus efeitos, objetivando selecionar as espécies mais eficientes.

Levantamentos feitos no Brasil também evidenciaram número variado de espécies associadas à cultura da mandioca. Em culturas da região do Sul de Minas Gerais, Siqueira et al. (1989) observaram 181 esporos por $100 \mathrm{~g}$ de solo, com predominância de A. scrobiculata e Gigaspora sp.

Nas últimas décadas tem sido observada a associação de bactérias diazotróficas associativas em diversas espécies de plantas, nos mais variados ecossistemas. O gênero mais estudado é o Azospirillum, com quatro espécies identificadas: $A$. brasilense, que ocorre principalmente em gramíneas $\mathrm{C}_{3}$ de clima temperado, A. lipoferum, em gramíneas tropicais do tipo $\mathrm{C}_{4}$ (Baldani et al., 1981),
A. amazonense, em várias gramíneas da Amazônia e do Rio de Janeiro (Magalhães et al., 1983) e A. halopraeferens, adaptado a solos salinos e altas temperaturas e associado a uma gramínea forrageira no Paquistão (Kallar grass) (Reinhold et al., 1987). Existem também vários estudos com bactérias pertencentes a outros gêneros, como Acetobacter, Herbaspirillum e Klebsiella (Boddey \& Döbereiner, 1988).

Há estudos da associação de bactérias diazotróficas com gramíneas forrageiras e cereais, como milho, trigo e sorgo (Tarrand et al., 1978; Baldani et al., 1986), em cana-de-açúcar (Cavalcante \& Döbereiner, 1988; Reis, 1994) e em batata-doce (Hill et al., 1983; Paula, 1992), o que evidencia a ocorrência generalizada e os efeitos benéficos das bactérias diazotróficas associativas (Boddey \& Döbereiner, 1988). Nestas duas últimas décadas, os estudos dessa associação permitiram o isolamento de várias novas bactérias diazotróficas associadas a inúmeras espécies de plantas.

Não há relatos, porém, sobre a contribuição da fixação biológica de nitrogênio (FBN) atmosférico por bactérias diazotróficas associadas à cultura da mandioca, embora Santana et al. (1985) tenham salientado essa necessidade, em decorrência da falta de respostas da cultura à aplicação de $\mathrm{N}$.

O objetivo do trabalho foi avaliar a ocorrência, isolar e identificar as espécies predominantes de fungos micorrízicos arbusculares e bactérias diazotróficas associadas à cultura da mandioca.

\section{MATERIAL E MÉTODOS}

\section{Levantamento preliminar de bactérias diazotróficas}

Foi realizado um levantamento preliminar da ocorrência de bactérias diazotróficas associadas à cultura da mandioca. Foram coletadas amostras de solo da rizosfera, raízes, tubérculos, manivas e folhas em dois locais na Embrapa-Centro Nacional de Pesquisa de Agrobiologia (CNPAB), Seropédica, RJ, em um Podzólico VermelhoAmarelo. Amostras de $10 \mathrm{~g}$ do tecido vegetal (raízes, tubérculos, manivas e folhas) e do solo foram trituradas em solução de sacarose a 5\%, em liquidificador, e submetidas a diluições sucessivas em solução de sacarose a $5 \%$, em concentrações de $10^{-2}$ a $10^{-6}$. Destas diluições, alíquotas de $0,1 \mathrm{~mL}$ foram transferidas para frascos de $10 \mathrm{~mL}$ com $5 \mathrm{~mL}$ dos seguintes meios semi-sólidos e isentos de 
N: LGI-P (Cavalcante \& Döbereiner, 1988), NFb-malato (Döbereiner, 1980) e os sais do NFb, tendo glicose, amido ou a mistura $3 \mathrm{~g}$ de glicose $+1 \mathrm{~g}$ de oxalato $+1 \mathrm{~g}$ de citrato por litro (NFb-GOC) como fonte de carbono, em três repetições. Os frascos foram incubados por cinco dias, a $28^{\circ} \mathrm{C}$, no escuro, avaliando-se, então, as características de crescimento (formação de película ou bolhas de gases).

\section{Ocorrência de bactérias diazotróficas}

Foram coletadas amostras de solo da rizosfera, raízes, tubérculos, manivas e folhas em cinco localidades do Estado do Rio de Janeiro, duas de São Paulo e dez do Paraná. Em cada localidade foram coletadas cinco plantas, com três repetições. O preparo das amostras, inoculação (meio LGI-P, NFb-malato e NFb-GOC) e condições de crescimento foram realizados conforme descrito no item anterior, também em três repetições. Após incubação, foi avaliado o crescimento microbiano, observando-se formação e migração de película característica em direção à superfície (crescimento em condições de microaerofilia) e/ou presença de bolhas (produção de gases), capacidade de alcalinizar ou acidificar o meio, e observação das colônias em microscópio (Döbereiner, 1988; Moreira, 1994). A quantificação das bactérias foi feita pela técnica do Número Mais Provável (NMP), utilizando-se a Tabela de Cochran, indicada por Alexander (1982). Dos frascos da última diluição com crescimento positivo foram feitas lâminas, para observação, em microscópio, a predominância dos microrganismos, e avaliada a atividade da nitrogenase através da técnica de Atividade de Redução de Acetileno (ARA) em cromatógrafo a gás com detector de ionização de chama, segundo Boddey (1987). Aquelas culturas que apresentaram maior atividade foram selecionadas para riscagem em placas-de-petri em seus respectivos meios sólidos (LGI-P, NFb-malato ou NFb-GOC). Destas riscagens, foram selecionadas as colônias predominantes, que foram transferidas para novos frascos com meio semi-sólido. Avaliou-se, então, a ARA das culturas, e aquelas em que se detectou atividade da nitrogenase foram novamente riscadas em placas contendo seus meios de origem, e em meio batata (Moreira, 1994), para checar sua pureza. Esses passos foram repetidos tantas vezes quantas necessárias para sua purificação. Foram feitos testes utilizando o amido como única fonte de carbono em substituição ao ácido málico no meio NFb, e também com a adição de $0,5 \%$ de caldo de tubérculo (diluído em água) e adicionado ao meio.

A mesma metodologia foi aplicada para quantificação e isolamento de bactérias diazotróficas de material vegetal (maniva, tubérculo e raiz) desinfestado, superficialmente, com hipoclorito de sódio a $1 \%$, por 10 minutos.

\section{Ocorrência de fungos micorrízicos arbusculares}

O solo da rizosfera das plantas amostradas foi homogeneizado e submetido ao peneiramento úmido (Gerdemann \& Nicolson, 1963). As amostras foram centrifugadas em solução de sacarose a $40 \%$, a $3.000 \mathrm{rpm}$ ( $1.000 \mathrm{~g}$ ), como descrito em Colozzi-Filho \& Balota (1994), para separação dos esporos do solo e posterior avaliação do número de esporos em placa com anéis concêntricos. As espécies foram identificadas com auxílio do manual elaborado por Schenck \& Perez (1987). As raízes finas $(500 \mathrm{mg})$ foram clarificadas e coradas, com base na metodologia de Phillips \& Hayman (1970), como descrito em Colozzi-Filho \& Balota (1994), e a colonização micorrízica foi avaliada pelo método da placa riscada (Giovannetti \& Mosse, 1980).

\section{Capacidade e eficiência de fixação biológica de $\mathbf{N}_{2}$ da Bactéria $\mathbf{E}$}

Preliminarmente, avaliou-se a estabilidade da capacidade de fixação biológica de $\mathrm{N}_{2}$ de oito estirpes da Bactéria $\mathrm{E}$, determinando-se a ARA e objetivando observar se estes isolados não perdiam a capacidade de FBN quando submetidos a repicagens consecutivas em meio YM (Vincent, 1970) com adequado suprimento de nitrogênio.

As estirpes testadas foram provenientes da rizosfera (E-21), de raízes desinfestadas (E-23) e lavadas (E-30a e E-31), do interior do tubérculo (E-34), de tubérculo desinfestado (E-28), e de maniva desinfestada (E-29) e lavada (E-30b) de mandioca. As repicagens sucessivas foram feitas em placas-de-petri com meio YM sólido, com $100 \mathrm{mg} / \mathrm{L}$ de extrato de levedura como fonte de N. Após as repicagens, os isolados foram inoculados em frascos com $6 \mathrm{~mL}$ de meio NFb-GOC, semi-sólido e isento de $\mathrm{N}$, avaliando-se a atividade da nitrogenase através da ARA, em cromatografia gasosa, aos 6, 9 e 12 dias após inoculação.

Após confirmada a estabilidade da capacidade de fixação, as estirpes foram repicadas para frascos com meio $\mathrm{NFb}-\mathrm{GOC}$, semi-sólido e isento de N, no escuro, avaliandose a ARA aos 3, 6, 9, 12, 15 e 18 dias após incubação a $28^{\circ} \mathrm{C}$. Aos 18 dias de incubação, os meios das culturas foram submetidos à análise de $\mathrm{N}$ total pelo método microKjeldahl. Utilizando-se a integração da curva de ARA no tempo e os resultados obtidos da análise do $\mathrm{N}$ total, calculou-se a relação entre mols de acetileno reduzidos a etileno (integrados no tempo) e de $\mathrm{N}$ acumulado no meio de cultura. A eficiência no uso da fonte de carbono (total de 1,62 $\mathrm{g}$ 
de carbono/L fornecidos pela glicose, oxalato e citrato) foi inferida através do $\mathrm{N}$ total acumulado no meio, presumindo-se, porém, que a fonte de carbono fora esgotada.

Em amostras dos solos após secadas ao ar, moídas e passadas em peneira de malha de $2 \mathrm{~mm}$, foram analisados o pH, a matéria orgânica, e teores de $\mathrm{P}, \mathrm{Ca}, \mathrm{Mg}, \mathrm{K}$ e Al, segundo Pavan et al. (1992).

\section{RESULTADOS E DISCUSSÃO}

\section{Levantamento preliminar de bactérias diazotróficas}

Os resultados do levantamento preliminar de bactérias diazotróficas mostraram a presença destas em todas as partes amostradas, exceto nas folhas da mandioca. Os meios utilizados para a avaliação, porém, apresentaram resultados diferenciados.

$\mathrm{O}$ meio $\mathrm{NFb}$-glicose apresentou contaminação elevada por fungos, dificultando, assim, o crescimento e a avaliação de bactérias diazotróficas. Já o meio $\mathrm{NFb}$-amido permitiu o crescimento e isolamento de algumas bactérias diazotróficas. Entretanto, em testes posteriores com culturas puras, em que foram utilizados os sais do meio $\mathrm{NFb}$ autoclavados com adição posterior, como fonte de carbono, de solução de amido, pré-esterilizada por filtragem (Millipore, 0,22 $\mu \mathrm{m}$ ), não se confirmou o crescimento dessas bactérias. Assim, o crescimento em NFb-amido provavelmente ocorreu pela utilização de açúcares provenientes da degradação do amido durante a autoclavagem. O meio $\mathrm{NFb}$-malato possibilitou o crescimento de microrganismos, com presença de bactérias pertencentes ao gênero Azospirillum. O meio LGI-P apresentou bons resultados na semi-seletividade de microrganismos diazotróficos do gênero Klebsiella. O meio $\mathrm{NFb}-\mathrm{GOC}$ também mostrou bons resultados na seletividade de alguns microrganismos com crescimento lento, ou seja, formação de película de crescimento em torno dos 10 dias de incubação. Por estes resultados, foram utilizados nas avaliações os meios LGI-P, NFb-malato e NFb-GOC.

\section{Ocorrência de bactérias diazotróficas}

A composição química dos solos amostrados nos Estados do Rio de Janeiro, São Paulo e Paraná, encontram-se na Tabela 1. Observa-se que o solo de Santa Cruz, RJ, apresentou altos teores de K, P e matéria orgânica. Os valores de $\mathrm{pH}$ e os teores dos elementos dos demais solos do Rio de Janeiro e São Paulo apresentaram-se dentro da média dos solos cultivados com a mandioca. No Paraná, o solo de Londrina apresentou maior fertilidade comparado às outras localidades, que apresentaram características bem próximas dos solos cultivados com a cultura, sendo ácidos e de baixa fertilidade.

Bactérias diazotróficas foram isoladas de todas as partes da planta, com exceção das folhas, em todas as localidades amostradas (Tabelas 2 e 3). Foram identificadas bactérias pertencentes ao gênero Klebsiella sp., a espécie Azospirillum lipoferum, e uma bactéria ainda não identificada, provavelmente não descrita, aqui referida como Bactéria E. Isolados da Bactéria tipo E foram obtidos, concomitantemente, na cultura do arroz (Oliveira, 1992) e da mandioca (Balota, 1994; Balota et al., 1994), sendo, posteriormente, classificados de maneira preliminar como uma nova espécie do gênero Burkholderia (Hartmann et al., 1995).

As bactérias diazotróficas isoladas da cultura da mandioca apresentam as seguintes características:

Klebsiella sp.: apresenta formação de bolhas e crescimento difuso em meio LGI-P semi-sólido, crescimento rápido e abundante com produção de lipopolissacarídeo em meio LGI-P sólido.

A. lipoferum: apresenta formação de película esbranquiçada e espessa em meio NFb-malato semisólido, presença de células pleomórficas em meio alcalino, e colônia leitosa e densa em meio NFb-malato sólido.

Bactéria E: apresenta crescimento lento, com película difusa subindo lentamente até o sexto dia e com fixação de $\mathrm{N}_{2}$ até o $18^{\circ}$ dia em meio NFb-GOC semi-sólido. As colônias são, inicialmente, transparentes, tornando-se maiores, com interior amarelo, bordos transparentes e redondos, e, posteriormente, contorno irregular, passando de amarelo para verde, e, depois, azul, em meio NFb-GOC sólido.

A bactéria Klebsiella sp. foi quantificada e isolada em meio LGI-P, um meio semi-seletivo usualmente utilizado para Acetobacter diazotrophicus, que não foi constatada em nenhuma das amostras. O meio LGI-P apresentou bons resultados para ava- 
TABELA 1.Composição química dos solos amostrados com a cultura da mandioca em várias localidades do Estado do Rio de Janeiro, São Paulo e Paraná. Médias de três repetições.

\begin{tabular}{|c|c|c|c|c|c|c|c|c|}
\hline Local & Solo $^{1}$ & $\begin{array}{c}\mathrm{pH} \\
\text { (água) }\end{array}$ & $\mathrm{Al}$ & $\mathrm{Ca}$ & $\mathrm{Mg}$ & $\mathrm{K}$ & $\mathrm{P}$ & MO \\
\hline & & & ---- & $----(\mathrm{cn}$ & g) ---. & -------- & $(\mathrm{mg} / \mathrm{kg})$ & $(\%)$ \\
\hline \multicolumn{9}{|l|}{ Rio de Janeiro } \\
\hline Seropédica & $\mathrm{P} 1$ & 5,5 & 0,0 & 1,2 & 0,7 & 0,18 & 2,3 & 2,13 \\
\hline Paracambi & PVAd & 4,8 & 0,8 & 1,1 & 0,5 & 0,11 & 3,9 & 1,97 \\
\hline Itaguaí I & PVAd & 4,1 & 1,0 & 0,6 & 0,5 & 0,12 & 2,8 & 2,04 \\
\hline Itaguaí II & PVA & 5,4 & 0,2 & 2,0 & 0,7 & 0,18 & 4,6 & 1,79 \\
\hline Sta. Cruz & $\mathrm{HO}$ & 4,5 & 5,8 & 0,9 & 0,6 & 0,47 & 24,0 & 12,34 \\
\hline \multicolumn{9}{|l|}{ São Paulo } \\
\hline Campinas & LV & 4,3 & 0,4 & 0,3 & 0,4 & 0,09 & 4,5 & 2,90 \\
\hline Piracicaba & LV & 5,0 & 0,8 & 2,1 & 1,1 & 0,31 & 3,4 & 1,20 \\
\hline \multicolumn{9}{|l|}{ Paraná } \\
\hline Altônia & PVA & 5,4 & 0,0 & 2,05 & 1,81 & 0,07 & 3,7 & 1,45 \\
\hline Paranavaí I & PVA & 4,5 & 0,2 & 1,43 & 0,70 & 0,07 & 2,2 & 1,52 \\
\hline Paranavaí II & PVA & 4,7 & 0,1 & 1,40 & 0,66 & 0,06 & 2,8 & 1,69 \\
\hline Umuarama & LEd & 5,1 & 0,0 & 1,43 & 0,62 & 0,22 & 8,7 & 1,29 \\
\hline Pérola & LEd & 5,2 & 0,0 & 1,75 & 0,33 & 0,12 & 10,5 & 1,22 \\
\hline São Jorge I & PVA & 6,1 & 0,0 & 3,05 & 0,78 & 0,27 & 11,3 & 1,29 \\
\hline São Jorge II & PVA & 5,7 & 0,0 & 1,50 & 0,58 & 0,20 & 8,7 & 0,91 \\
\hline Cafezal do Sul I & PVA & 5,4 & 0,0 & 1,48 & 0,41 & 0,17 & 9,0 & 0,94 \\
\hline Cafezal do Sul II & PVA & 6,0 & 0,0 & 1,75 & 0,82 & 0,20 & 10,2 & 0,91 \\
\hline Londrina & LRd & 4,6 & 0,2 & 4,3 & 1,9 & 0,43 & 18,6 & 2,60 \\
\hline
\end{tabular}

${ }^{1}$ Pl: Planossolo; PVAd: Podzólico Vermelho-Amarelo distrófico; PVA: Podzólico Vermelho-Amarelo; LV: Latossolo Vermelho-Amarelo; HO: Orgânico; LEd: Latossolo Vermelho-Escuro distrófico; LRd: Latossolo Roxo distrófico.

TABELA 2. Ocorrência de bactérias diazotróficas nas diferentes partes da planta e na rizosfera de mandioca provenientes de amostras coletadas no Estado do Rio de Janeiro e de São Paulo. Média de três repetições ${ }^{1}$.

\begin{tabular}{|c|c|c|c|c|c|c|c|c|c|c|c|c|c|c|c|}
\hline \multirow[t]{2}{*}{ Local } & \multicolumn{3}{|c|}{ Maniva } & \multicolumn{3}{|c|}{$\begin{array}{l}\text { Casca do } \\
\text { tubérculo }\end{array}$} & \multicolumn{3}{|c|}{$\begin{array}{c}\text { Interior do } \\
\text { tubérculo }\end{array}$} & \multicolumn{3}{|c|}{ Raiz } & \multicolumn{3}{|c|}{ Rizosfera } \\
\hline & $\mathrm{Kb}$ & $\mathrm{Az}$ & $\mathrm{bE}$ & $\mathrm{Kb}$ & $\mathrm{Az}$ & $\mathrm{bE}$ & $\mathrm{Kb}$ & $\mathrm{Az}$ & $\mathrm{bE}$ & $\mathrm{Kb}$ & $\mathrm{Az}$ & $\mathrm{bE}$ & $\mathrm{Kb}$ & $\mathrm{Az}$ & $\mathrm{bE}$ \\
\hline & & & & 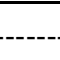 & ---- & úme & de $b$ & térias & $\times 10^{5}$ & & & & & & \\
\hline \multicolumn{16}{|c|}{ Rio de Janeiro } \\
\hline Seropédica & 11,0 & 1,1 & 2,8 & 9,4 & 4,5 & 2,9 & 4,3 & 0,4 & 0,1 & 3,6 & 2,8 & 0,8 & 5,2 & 3,4 & 0,9 \\
\hline Paracambi & 6,3 & 14,0 & 1,3 & 9,5 & 5,2 & 1,5 & 2,7 & 1,8 & 1,1 & 5,5 & 4,0 & 2,0 & 3,6 & 2,0 & 0,3 \\
\hline Itaguaí I & 11,0 & 11,0 & 4,5 & 2,5 & 4,5 & 0,5 & 0,9 & 0,5 & 0,5 & 1,1 & 0,5 & 1,1 & 11,0 & 1,1 & 0,2 \\
\hline Itaguaí II & 4,2 & 0,7 & 2,9 & 9,5 & 5,8 & 1,2 & 0,7 & 0,9 & 0,3 & 2,4 & 3,6 & 1,5 & 6,3 & 4,3 & 0,9 \\
\hline Santa Cruz & 5,1 & 1,4 & 4,5 & 1,5 & 0,3 & 1,4 & 1,1 & 0,1 & 0,1 & 0,7 & 0,2 & 2,0 & 2,5 & 1,1 & 0,2 \\
\hline \multicolumn{16}{|l|}{ São Paulo } \\
\hline Campinas & 3,1 & 3,5 & 1,7 & 0,9 & 2,5 & 0,1 & 0,9 & 0,9 & 0,1 & 41,0 & 1,0 & 1,1 & 46,0 & 7,3 & 0,3 \\
\hline Piracicaba & 29,0 & 11,0 & 2,2 & 0,5 & 4,5 & 1,1 & 0,5 & 0,4 & 0,2 & 19,0 & 2,3 & 1,5 & 21,0 & 0,9 & 0,5 \\
\hline
\end{tabular}

${ }^{1} \mathrm{~Kb}$ : Klebsiella sp., Az: Azospirillum lipoferum, bE: Bactéria E, que estavam predominantemente nos meios semi-sólidos e isentos de N, LGI-P, $\mathrm{NFb}$-malato e NFb-GOC, respectivamente. 
liação da ocorrência de bactérias do gênero Klebsiella sp., com alta ARA em meio semi-sólido. Este meio se mostrou apropriado para avaliação de Klebsiella sp., assim como observações feitas na cultura da batata-doce (Paula, 1992).

Os meios LGI-P e NFb-GOC suplementados com $0,5 \%$ de caldo de tubérculo de mandioca, não apresentaram melhor eficiência que os meios sem suplementação. Além disso, a suplementação com caldo de tubérculo favoreceu o desenvolvimento de fungos, prejudicando o desenvolvimento e a avaliação de bactérias, como observado no levantamento preliminar com a utilização de NFb-amido. Estas observações não são concordantes com as obtidas por Paula (1992), em que a utilização do meio suplementado com caldo de batata-doce propiciou melhor crescimento de Klebsiella sp.

Os dados das Tabelas 2 e 3 mostram a ocorrência generalizada de Klebsiella sp., A. lipoferum e Bactéria $\mathrm{E}$ em todas as localidades; não foram observadas diferenças acentuadas conforme as características químicas do solo ou das cultivares Vassourinha e Saracura no Rio de Janeiro, Branca de Santa Catarina em São Paulo, e Fibra e Pioneira no Paraná.

De modo geral, nas partes da planta estudadas (maniva, casca do tubérculo, interior do tubérculo, raízes e rizosfera) em todas as localidades, os números de Klebsiella sp. e A. lipoferum, foram superiores ao da Bactéria E. Com relação a Klebsiella sp. e A. lipoferum, foram observados números mais elevados nas raízes e rizosfera e menores no interior do tubérculo. Estas bactérias também foram observadas, porém em menores números, em material vegetal desinfestado superficialmente, o que sugere sua ocorrência em regiões mais internas do córtex (Tabela 4).

O número elevado de bactérias diazotróficas associadas à maniva sugere a potencialidade da transmissão de microrganismos através de material vegetal, confirmando observações já feitas em canade-açúcar (Paula et al., 1991; Reis, 1994) e em batata-doce (Paula, 1992), na qual houve tendência de as partes inferiores das ramas apresentarem maiores números de $A$. diazotrophicus.

O número de microrganismos diazotróficos presentes no interior do tubérculo foi inferior ao observado em outras partes da planta, não ocorrendo o mesmo que o observado na cana-de-açúcar (Paula et al., 1991) e na batata-doce (Paula, 1992), em que o número de microrganismos diazotróficos foi relacionado ao teor de carboidrato do tecido vegetal (sacarose ou amido). No teste feito, foi constatado que os isolados obtidos (Klebsiella sp.,

TABELA 3.Ocorrência de bactérias diazotróficas nas diferentes partes da planta e na rizosfera de mandioca provenientes de amostras coletadas no Estado do Paraná. Média de três repetições ${ }^{1}$.

\begin{tabular}{|c|c|c|c|c|c|c|c|c|c|c|c|c|}
\hline \multirow[t]{2}{*}{ Local } & \multicolumn{3}{|c|}{ Maniva } & \multicolumn{3}{|c|}{ Tubérculo } & \multicolumn{3}{|c|}{ Raiz } & \multicolumn{3}{|c|}{ Rizosfera } \\
\hline & $\mathrm{Kb}$ & $\mathrm{Az}$ & $\mathrm{bE}$ & $\mathrm{Kb}$ & $\mathrm{Az}$ & $\mathrm{bE}$ & $\mathrm{Kb}$ & $\mathrm{Az}$ & $\mathrm{bE}$ & $\mathrm{Kb}$ & $\mathrm{Az}$ & $\mathrm{bE}$ \\
\hline & 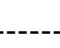 & & & 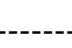 & (Nú & ro de & actéri & $x 10$ & g) -- & & & \\
\hline Altônia & 7,7 & 1,5 & 1,5 & 11,0 & 0,5 & 0,9 & 25,0 & 3,3 & 2,2 & 36,0 & 2,7 & 1,6 \\
\hline Paranavaí I & 4,6 & 3,7 & 0,7 & 26,0 & 3,5 & 1,2 & 28,0 & 6,8 & 0,3 & 41,0 & 2,1 & 3,8 \\
\hline Paranavaí II & 7,9 & 0,5 & 0,3 & 27,0 & 0,6 & 0,3 & 18,0 & 1,5 & 1,0 & 16,0 & 2,8 & 5,4 \\
\hline Umuarama & 1,5 & 1,5 & 1,0 & 10,2 & 0,2 & 0,3 & 12,0 & 0,9 & 0,1 & 10,9 & 4,9 & 0,4 \\
\hline Pérola & 2,8 & 4,9 & 2,7 & 1,5 & 0,2 & 0.4 & 0,7 & 2,1 & 0,3 & 14,6 & 4,7 & 0,9 \\
\hline São Jorge I & 4,9 & 3,1 & 0,2 & 0,5 & 0,7 & 0,4 & 4,4 & 4,6 & 1,5 & 14,6 & 15,8 & 0,4 \\
\hline São Jorge II & 2,1 & 0,7 & 1,5 & 0,2 & 0,7 & 0,9 & 3,7 & 4,5 & 0,9 & 9,8 & 4,9 & 0,3 \\
\hline Cafezal do Sul I & 3,1 & 1,4 & 0,4 & 3,1 & 1,5 & 0,1 & 4,9 & 2,8 & 2,0 & 36,2 & 13,1 & 1,5 \\
\hline Cafezal do Sul II & 3,6 & 4,9 & 0,2 & 1,4 & 4,6 & 0,1 & 3,5 & 14,9 & 2,8 & 21,5 & 7,1 & 1,4 \\
\hline Londrina & 1,7 & 1,3 & 0,2 & 4,6 & 0,8 & 0,2 & 13,5 & 3,4 & 1,4 & 10,4 & 4,8 & 0,9 \\
\hline
\end{tabular}

${ }^{1} \mathrm{~Kb}$ : Klebsiella sp., Az: Azospirillum lipoferum, bE: Bactéria E, que estavam predominantemente nos meios semi-sólidos e isentos de N, LGI-P, $\mathrm{NFb}$-malato e NFb-GOC, respectivamente. 
A. lipoferum e Bactéria E) não possuem a capacidade de utilizar o amido como fonte de carbono.

\section{Ocorrência de fungos micorrízicos arbusculares}

A colonização de raízes, a densidade de esporos e as espécies de fungos MA observadas nas várias localidades amostradas encontram-se na Tabela 5 . A percentagem de colonização apresentou valores que variaram de 31 a $49 \%$ no RJ, 33 a $46 \%$ em SP, e de 31 a $71 \%$ no PR. Os menores valores (31\%) foram observados nos solos de maior fertilidade, ou seja, o solo orgânico em Santa Cruz, RJ e o latossolo roxo, com altos teores de P, em Londrina, PR.

De modo geral, as taxas de colonização micorrízica podem ser consideradas elevadas, se comparadas com os valores observados por Siqueira et al. (1989) na região sul do Estado de Minas Gerais, e aos valores de Dodd et al. (1990) na Colômbia, também em condições naturais nessa mesma cultura.

Os valores da densidade de esporos observados no Rio de Janeiro (159 a 384) e São Paulo (193 a 215) são considerados altos, enquanto que os do Paraná (10 a 168) são pouco inferiores às outras observações na cultura da mandioca, no Brasil. Estes valores são, até certo ponto, comparáveis aos 181 observados por Siqueira et al. (1989) na região sul do Estado de Minas Gerais. Os valores, entretanto, são bastante inferiores aos 2.800 esporos por $100 \mathrm{~mL}$, observados por Sieverding (1991) na Colômbia. Contudo, observações de Dodd et al. (1990), também na Colômbia, constataram
110 esporos por $100 \mathrm{~mL}$ de solo, o que evidencia a grande variabilidade que pode ocorrer conforme as características físicas, químicas ou biológicas do solo.

Os dados evidenciam a ocorrência de várias espécies de FMA, associadas à cultura da mandioca nas localidades estudadas. No Estado do Rio de Janeiro, houve predominância de Entrophospora colombiana, Acaulospora scrobiculata e Scutellospora heterogama. No Estado de São Paulo, houve predominância de $A$. scrobiculata e $S$. heterogama em Piracicaba, e A. appendicula e S. pellucida em Campinas. No Estado do Paraná, a predominância de ocorrência foi de $A$. scrobiculata, $S$. heterogama, S. pellucida e G. deserticula (Tabela 5). Variado número de espécies associadas à cultura da mandioca já havia sido constatado em culturas da região do Sul de Minas Gerais por Siqueira et al. (1989), que observaram predominância de A. scrobiculata e Gigaspora sp. Em trabalhos desenvolvidos na Colômbia, Sieverding (1991) observou grande número de esporos pertencente a 12 espécies, com predominância de Acaulospora sp., E. colombiana, G. fasciculatum e A. appendicula, enquanto que Dodd et al. (1990) observaram predominância de G. occultum, A. myriocarpa, E. colombiana, A. mellea, A. morrowae e G. fasciculatum. Entretanto, deve ser salientado que nem todas espécies associadas naturalmente à cultura são eficientes, pois sabe-se que as espécies de FMA apresentam efeito diferenciado nas plantas hospedeiras, como observado nos estudos de Howeler et al. (1987), em que apenas $40 \%$ de 150 isolados de FMA testados apre-

TABELA 4. Ocorrência de bactérias diazotróficas nas diferentes partes da planta de mandioca desinfestadas superficialmente. Médias de três repetições ${ }^{1}$.

\begin{tabular}{|c|c|c|c|c|c|c|c|c|c|}
\hline \multirow[t]{2}{*}{ Local } & \multicolumn{3}{|c|}{ Maniva } & \multicolumn{3}{|c|}{ Tubérculo } & \multicolumn{3}{|c|}{ Raiz } \\
\hline & $\mathrm{Kb}$ & $\mathrm{Az}$ & $\mathrm{bE}$ & $\mathrm{Kb}$ & $\mathrm{Az}$ & $\mathrm{bE}$ & $\mathrm{Kb}$ & $\mathrm{Az}$ & $\mathrm{bE}$ \\
\hline & & & & Núm & e bac & x 10 & - & & ---- \\
\hline Altônia & 2,1 & 0,8 & 1,2 & 4,9 & 1,2 & 1,5 & 7,5 & 3,1 & 0,5 \\
\hline Paranavaí I & 1,1 & 1,5 & 3,1 & 2,4 & 2,3 & 0,2 & 5,0 & 4,9 & 0,3 \\
\hline Umuarama & 1,0 & 2,5 & 0,1 & 6,8 & 4,9 & 0,2 & 4,6 & 11,0 & 1,2 \\
\hline Pérola & 1,5 & 1,5 & 0,4 & 3,1 & 4,0 & 0,9 & 10,0 & 9,8 & 0,1 \\
\hline São Jorge I & 7,3 & 3,0 & 0,6 & 1,4 & 1,2 & 0,2 & 11,0 & 12,4 & 4,4 \\
\hline
\end{tabular}

${ }^{1} \mathrm{~Kb}$ : Klebsiella sp., Az: Azospirillum lipoferum, bE: Bactéria E, que estavam predominantemente nos meios semi-sólidos e isentos de N, LGI-P, $\mathrm{NFb}$-malato e NFb-GOC, respectivamente. 
TABELA 5. Colonização micorrízica, densidade de esporos e espécies de fungos MA associadas à cultura da mandioca em amostras coletadas no Estado do Rio de Janeiro, São Paulo e Paraná. Médias de três repetições.

\begin{tabular}{|c|c|c|c|}
\hline Local & $\begin{array}{l}\text { Colonização } \\
\text { micorrízica }\end{array}$ & $\begin{array}{l}\text { Densidade de } \\
\text { esporos }\end{array}$ & Espécies de fungos $\mathrm{MA}^{1}$ \\
\hline & $(\%)$ & $\left(\mathrm{n}^{\mathrm{o}} / 100 \mathrm{~mL}\right)$ & \\
\hline \multicolumn{4}{|l|}{ Rio de Janeiro } \\
\hline Seropédica & 39 & 197 & $\begin{array}{l}\text { E. colombiana, A. scrobiculata, S. heterogama e } \\
\text { Glomus sp. }\end{array}$ \\
\hline Paracambi & 46 & 384 & $\begin{array}{l}\text { E. colombiana, A. appendicula, G. occultum, } \\
\text { Entrophospora sp., Scutellospora sp. } \\
\text { e Glomus sp. }\end{array}$ \\
\hline Itaguaí I & 49 & 322 & $\begin{array}{l}\text { A. scrobiculata, E. colombiana, } \\
\text { A. appendicula e Glomus sp. }\end{array}$ \\
\hline Itaguaí II & 42 & 159 & $\begin{array}{l}\text { A. scrobiculata, G. margarita, S. heterogama, } \\
\text { Entrophospora sp. e Glomus sp. }\end{array}$ \\
\hline Santa Cruz & 31 & 268 & E. colombiana, A. scrobiculata e Glomus sp. \\
\hline $\begin{array}{l}\text { São Paulo } \\
\text { Campinas }\end{array}$ & 33 & 193 & $\begin{array}{l}\text { A. appendicula, S. pellucida, G. margarita, } \\
\text { Entrophospora } \mathrm{sp.} \text { e Glomus tenuis }\end{array}$ \\
\hline Piracicaba & 46 & 215 & $\begin{array}{l}\text { A. scrobiculata, S. heterogama, G. margarita, } \\
\text { Entrophospora sp. e Glomus sp. }\end{array}$ \\
\hline \multicolumn{4}{|l|}{ Paraná } \\
\hline Altônia & 56 & 42 & $\begin{array}{l}\text { A. scrobiculata, G. deserticola, S. pellucida, } \\
\text { S. heterogama e Gigaspora sp. }\end{array}$ \\
\hline Paranavaí & 69 & 72 & $\begin{array}{l}\text { A. scrobiculata, S. heterogama, S. pellucida, } \\
\text { G. deserticula, Gigaspora sp.1. } \\
\text { e Gigaspora sp.2. }\end{array}$ \\
\hline Paranavaí II & 52 & 88 & A. scrobiculata, S. heterogama e $S$. pellucida \\
\hline Umuarama & 43 & 168 & $\begin{array}{l}\text { A. scrobiculata, S. pellucida, G. margarita } \\
\text { e Glomus sp. }\end{array}$ \\
\hline Pérola & 53 & 68 & S. heterogama, S. pellucida e G. margarita \\
\hline São Jorge I & 67 & 32 & $\begin{array}{l}\text { S. heterogama, S. pellucida, A. scrobiculata, } \\
\text { G. margarita e Gigaspora sp. }\end{array}$ \\
\hline São Jorge II & 71 & 14 & A. scrobiculata, G. margarita e Gigaspora sp. \\
\hline Cafezal do Sul I & 40 & 20 & $\begin{array}{l}\text { S. heterogama, A. scrobiculata, S. pellucida, } \\
\text { Glomus sp. e Entrophospora sp. }\end{array}$ \\
\hline Cafezal do Sul II & 47 & 10 & $\begin{array}{l}\text { G. margarita, S. appendicula, Glomus sp. } \\
\text { e Scutellospora sp. }\end{array}$ \\
\hline Londrina & 31 & 63 & $\begin{array}{l}\text { A. scrobiculata, S. pellucida, } \\
\text { S. heterogama e G. margarita }\end{array}$ \\
\hline
\end{tabular}

${ }^{1}$ Em ordem decrescente de ocorrência. 
sentaram eficiência na absorção de P, e por Sieverding \& Toro (1986), citados por Sieverding (1991), que verificaram que apenas 15\% de 204 isolados de FMA testados foram eficientes.

As razões dessas variações interespecíficas dos FMA podem estar relacionadas à capacidade fisiológica intrínseca de cada espécie em infectar e colonizar as raízes e absorver e translocar os nutrientes. Isolados da mesma espécie provenientes de locais diferentes (ecótipos) podem apresentar, ainda, efeito diferenciado de eficiência nas plantas. As causas das variações intra-específicas ainda não são conhecidas, podendo resultar das pressões seletivas diferenciadas do ambiente. Cabe observar que as técnicas taxonômicas usuais na classificação dos FMA não permitem a diferenciação precisa de espécies com características intermediárias que poderiam ser tomadas como ecótipos.

De um modo geral, os resultados mostram que a cultura da mandioca apresenta alta taxa de colonização de raízes com várias espécies de fungos MA associadas, apesar da grande variabilidade de solos, condições climáticas e manejo da cultura.

\section{Capacidade e eficiência de FBN da Bactéria $\mathrm{E}$}

Os dados da Tabela 6 mostram que as estirpes da Bactéria E, após dez repicagens, mantiveram seus níveis de eficiência de fixação biológica de $\mathrm{N}_{2}$ similares às mantidas no estoque. Isto evidencia que a Bactéria E apresenta capacidade de FBN estável, e não como ocorre em muitos casos de microrganismos, que adquirem a capacidade de FBN, por processos de transformação e/ou conjugação, quando os genes determinantes da capacidade FBN ficam situados em plasmídeos, que podem ser facilmente perdidos em meios com suprimento adequado de N.

Os valores da ARA das estirpes da Bactéria E no meio NFb-GOC aos 3, 6, 9, 12, 15 e 18 dias após inoculação encontram-se na Tabela 7. O pico de atividade da Bactéria E ocorreu aos 12 dias após a inoculação. Através da integração destes valores no tempo, obteve-se a quantidade total de acetileno reduzido a etileno, que variou de 16,0 a 27,3 $\mu$ mols. A análise de $\mathrm{N}$ total acumulado no meio variou de 5,3 a 10,3 umols de N. A relação quantidade de acetileno reduzido/ $\mathrm{N}$ total acumulado no meio variou de 1,66 a 4,38. Com os valores de $\mathrm{N}$ total acumulado no meio e a quantidade de $\mathrm{C}$ fornecida $(1,62 \mathrm{~g} / \mathrm{L})$, considerando-se que todo $\mathrm{C}$ foi utilizado, pode-se calcular uma relação de 7,63 a $14,84 \mathrm{mg} \mathrm{N}$ acumulou no meio por $\mathrm{g}$ de $\mathrm{C}$ fornecido. Estes valores são inferiores aos observados em A. lipoferum, A. brasilense e A. amazonense, de 24, 29 e $31 \mathrm{mg} \mathrm{N} / \mathrm{g}$ de carbono, respectivamente (Okon et al., 1976; Neyra \& Döbereiner, 1977; Magalhães et al., 1983). Além destas características, tem sido evidenciado que a Bactéria E produz

TABELA 6. Valores da ARA de estirpes da Bactéria E em meio NFb-GOC, mantidos no estoque e após passarem por uma dezena de repicagens, em meio YM suplementado com nitrogênio. Médias de três repetições.

\begin{tabular}{|c|c|c|c|c|c|c|}
\hline \multirow[t]{3}{*}{ Estirpe } & \multicolumn{6}{|c|}{ Dias após inoculação } \\
\hline & \multicolumn{3}{|c|}{ Mantidas no estoque } & \multicolumn{3}{|c|}{ Após 10 repicagens } \\
\hline & 6 & 9 & 12 & 6 & 9 & 12 \\
\hline & & . & $(\mathrm{nmo}$ & ra) & & --- \\
\hline E-21 & 37 & 98 & 149 & 21 & 100 & 160 \\
\hline E-23 & 24 & 77 & 103 & 39 & 68 & 99 \\
\hline E-28 & 24 & 70 & 143 & 14 & 72 & 130 \\
\hline E-29 & 22 & 56 & 116 & 33 & 98 & 133 \\
\hline E-30a & 19 & 63 & 171 & 43 & 86 & 129 \\
\hline$E-30 b$ & 21 & 82 & 102 & 51 & 91 & 123 \\
\hline E-31 & 24 & 63 & 89 & 30 & 52 & 93 \\
\hline E-34 & 22 & 47 & 83 & 40 & 61 & 109 \\
\hline
\end{tabular}


TABELA 7. Valores da ARA, integrados para 18 dias, do $\mathbf{N}$ total acumulado, das relações de acetileno reduzido/ $\mathrm{N}$ acumulado e $\mathrm{N}$ acumulado/carbono fornecido de estirpes da Bactéria $\mathrm{E}$ em meio NFb-GOC. Médias de três repetições.

\begin{tabular}{lcccc}
\hline Estirpes & $\mathrm{C}_{2} \mathrm{H}_{4}$ Total & $\begin{array}{c}\text { N Total } \\
\text { acumulado }\end{array}$ & $\begin{array}{c}\text { Acetileno reduzido/ } \\
\text { N acumulado }\end{array}$ & $\begin{array}{c}\text { N acumulado/ } \\
\text { carbono fornecido }\end{array}$ \\
\hline E-21 & $(\mu$ mols $)$ & $(\mu$ mols $)$ & & $(\mathrm{mg} / \mathrm{g})$ \\
E-23 & 27,3 & 9,0 & 3,03 & 12,96 \\
E-28 & 19,0 & 9,1 & 2,09 & 13,11 \\
E-29 & 22,2 & 6,7 & 3,31 & 9,65 \\
E-30a & 18,8 & 7,0 & 2,69 & 10,08 \\
E-30b & 23,2 & 5,3 & 4,38 & 7,63 \\
E-31 & 19,7 & 9,9 & 1,99 & 14,26 \\
E-34 & 17,1 & 10,3 & 1,66 & 14,84 \\
\hline
\end{tabular}

substâncias estimulatórias do crescimento de plantas, como o ácido indol acético (Balota et al., 1995).

\section{CONCLUSÕES}

1. Ocorre um elevado número das bactérias diazotróficas Klebsiella sp., Azospirillum lipoferum e Bactéria E (Burkholderia), associadas às raízes, tubérculos, manivas e em solo rizosférico da mandioca.

2. Ocorrem várias espécies de fungos micorrízicos arbusculares associadas à cultura de mandioca, com predominância de E. colombiana, A. scrobiculata, A. appendicula, S. pellucida e S. heterogama.

3. A Bactéria E mantém estável sua capacidade de fixar $\mathrm{N}_{2}$ após dez repicagens sucessivas em meio suplementado com $\mathrm{N}$.

\section{AGRADECIMENTOS}

Aos pesquisadores José Ivo Baldani e Vera Lucia D. Baldani, da Embrapa-CNPAB, pelas sugestões e auxílio nas identificações das espécies de Azospirillum.

\section{REFERÊNCIAS}

ALEXANDER, M. Most probable number method of microbial populations. In: PAGE, A.L.; MILHER, R.H.; KEENEY, D.R. (Eds.). Methods of soil analysis. Part 2. Chemical and microbiological properties. Madison: American Society of Agronomy, 1982. p. $815-820$.

BALDANI, J.I.; PEREIRA, P.A.A.; ROCHA, R.E.M. da; DÖBEREINER, J. Especificidade na infecção de raízes por Azospirillum spp. em plantas com via fotossintética $\mathrm{C}_{3} \mathrm{e}_{4}$. Pesquisa Agropecuária Brasileira, Brasília, v.16, n.3, p.325-330, maio/jun. 1981.

BALDANI, V.L.D.; ALVAREZ, M.A.; BALDANI, J.I.; DÖBEREINER, J. Establishment of inoculated Azospirillum spp. in the rhizosphere and in roots of field-grown wheat and sorghum. Plant and Soil, Dordrecht, v.90, p.35-46, 1986.

BALOTA, E.L. Interação de bactérias diazotróficas e fungos micorrízicos vesículo-arbusculares na cultura da mandioca (Manihot esculenta Crantz). Itaguaí: UFRRJ, 1994. 281p. Tese de Doutorado.

BALOTA, E.L.; HUNGRIA, M.; DÖBEREINER, J. Occurrence of diazotrophic bacteria and vesiculararbuscular mycorrhizal fungi associated with cassava (Manihot esculenta Crantz). In: INTERNATIONAL SYMPOSIUM ON NITROGEN FIXATION WITH NON-LEGUMES, 6., 1993, Ismailia, Cairo. Proceedings... Giza: Cairo Univ., 1994. p.53-58.

BALOTA, E.L.; LOPES, E.S.; HUNGRIA, M.; DÖBEREINER, J. Interações e efeitos fisiológicos de bactérias diazotróficas e fungos micorrízicos arbusculares na mandioca. Pesquisa Agropecuária Brasileira, Brasília, v.30, n.11, p.1335-1345, nov. 1995.

BODDEY, R.M. Methods for quantification of nitrogen fixation associated with gramineae. CRC Critical 
Review Plant Science, Boca Raton, v.6, p.209-266, 1987.

BODDEY, R.M.; DÖBEREINER, J. Nitrogen fixation associated with grasses and cereals: recent results and perspectives for future research. Plant and Soil, Dordrecht, v.108, p.53-65, 1988.

CAVALCANTE, V.A.; DÖBEREINER, J. A new acidtolerant nitrogen-fixing bacterium with sugarcane. Plant and Soil, Dordrecht, v.108, p.23-31, 1988.

COCK, J.H.; HOWELER, R.H. The ability of cassava to grow on poor soils. In: JUNG, G.A. (Ed.). Crop tolerance to sub-optimal land conditions. Madison: American Society of Agronomy, 1978. v.32, p.145-154.

COLOZZI-FILHO, A.; BALOTA, E.L. Micorrizas arbusculares. In: HUNGRIA, M.; ARAÚJO, R.S. (Eds.). Manual de métodos empregados em estudos de microbiologia agrícola. Brasília: EmbrapaSPI, 1994. p.383-418.

DÖBEREINER, J. Forage grasses and grain crops. In: BERGENSEN, F.J. (Ed.). Methods for evaluating biological nitrogen fixation. New York: John Wiley \& Sons, 1980. p.535-555.

DÖBEREINER, J. Isolation and identification of root associated diazotrophs. Plant and Soil, Dordrecht, v.110, p.207-212, 1988.

DODD, J.C.; ARIAS, I.; KOOMEN, I.; HAYMAN, D.S. The mangement of populations of vesicular-arbuscular mycorrhizal fungi in acid-infertile soils of savana ecosystem. II. The effects of pre-crops on the spore populations of native and introduced VAM-fungi. Plant and Soil, Dordrecht, v.122, p.229240, 1990.

GERDEMANN, J.W.; NICOLSON, T.H. Spores of mycorrhizal endogone species extracted from soil by wet sieving and decating. Transactions of the British Mycological Society, London, v.46, p.235-246, 1963.

GIOVANNETTI, M.; MOSSE, B. An evaluation of techniques for measuring vesicular-arbuscular mycorrhizal infection in roots. New Phytologist, London, v.84, p.489-500, 1980.

GOMES, J.C. Considerações sobre adubação e calagem para a cultivar da mandioca. Revista Brasileira de Mandioca, Cruz das Almas, v.6, p.99-107, 1987.
HARTMANN, A.; BALDANI, J.I.; KIRCHHOF, G.; ABMUS, B.; HUTZLER, P.; SPRINGER, N.; LUDWIG, W.; BALDANI, V.L.; DÖBEREINER, J. Taxonomic and ecologic studies of diazotrophic rhizosphere bacteria using phylogenetic probes. In: FENDRIK, I.; GALLO, M.; VANDERLEYDEN, J.; ZAMAROCZY, M. (Eds.). Azospirillum VI and related microorganisms: genetics, physiology, ecology. Berlin: Springer-Verlag, 1995. p.415-427.

HILL, W.A.; BACON-HILL, P.; CROSSMAN, S.M.; STENVENS, C. Characterization of $\mathrm{N}_{2}$-fixing bacteria associated with sweet potato roots. Canadian Journal of Microbiology, Ottawa, v.28, p.860-862, 1983.

HOWELER, R.H. Nutrición mineral y fertilización de la yuca (Manihot esculenta Crantz). Cali: Centro Internacional de Agricultura Tropical, 1981a. 55p.

HOWELER, R.H. The effect of mycorrhizal on the phosphorus nutrition cassava. In: RUSSEL, R.S.; IGUE, K.; MEHTA, Y.R. (Eds.). The soil/root system in relation to brazilian agriculture. Londrina: IAPAR, 1981b. p.243-258.

HOWELER, R.H.; SIEVERDING, E.; SAIF, R.S. Pratical aspects of mycorrhizal technology tropical crops and pasture. Plant and Soil, Dordrecht, v.100, p.249-283, 1987.

MAGALHÃES, F.M.M.; BALDANI, J.I.; SOUTO, S.M.; KUYKENDALL, J.R.; DÖBEREINER, J. A new acid-tolerant Azospirillum species. Anais da Academia Brasileira de Ciências, Rio de Janeiro, v.55, p.417-430, 1983.

MOREIRA, F.M.S. Métodos de isolamento e identificação de microrganismos associativos fixadores de $\mathrm{N}_{2}$. In: HUNGRIA, M.; ARAÚJO, R.S. (Eds.). Manual de métodos empregados em estudos de microbiologia agrícola. Brasília: Embrapa-SPI, 1994. p.337-353.

NEYRA, C.A.; DÖBEREINER, J. Nitrogen fixation in grasses. Advances Agronomy, San Diego, v.29, p.1-38, 1977.

OKON, Y.; ALBRECHT, S.L.; BURRIS, R.H. Factors affecting growth and nitrogen fixation of Spirillum lipoferum. Journal of Bacteriology, Washington, v.125, p.1248-1254, 1976.

OLIVEIRA, E. de. Bactérias diazotróficas na cultura de arroz irrigado. Itaguaí: UFRRJ, 1992. 96p. Dissertação de Mestrado. 
PAULA, M.A. Interação micorrizas vesículoarbusculares e bactérias diazotróficas em batata-doce (Ipomoea batatas (L) Lam). Itaguaí: UFRRJ, 1992. 168p. Tese de Doutorado.

PAULA, M.A.; REIS, V.M.; DÖBEREINER, J. Interactions of Glomus clarum with Acetobacter diazotrophicus in infection of sweet potato (Ipomoea batatas), sugarcane (Saccharum spp.) and sweet sorghum (Sorghum vulgare). Biology and Fertility of Soils, Berlin, v.11, p.111-115, 1991.

PAVAN, M.A.; BLOCH, M. de F.; ZEMPLSKI, H. da C.; MIYAZAWA, M.; ZOCOLER, D.C. Manual de análise química de solo e controle de qualidade. Londrina: IAPAR, 1992. 40p. (Circular técnica, 76).

PHILLIPS, J.M.; HAYMAN, D.S. Improved procedures for clearing roots and staining parasitic and vesiculararbuscular mycorrhizal for rapid assessment of infection. Transactions of the British Mycological Society, London, v.55, p.158-161, 1970.

REINHOLD, B.; HUREK, T.; FENDRIK, I.; POT, B.; GILLIS, M.; KERSTERS, K.; THIELEMANS, S.; DE LEY, J. Azospirillum halopraeferens sp. nov., a nitrogen-fixing organism associated with roots of Kallar grass (Leptochloa fusca (L.) Kunth). International Journal of Systematic Bacteriology, Washington, v.37, p.43-51, 1987.

REIS, V.M. Estudos de infecção e métodos de detecção da bactéria endófita Acetobacter diazotrophicus em associação com a cana-de-açúcar. Itaguaí: UFRRJ, 1994. 231p. Tese de Doutorado.
SANTANA, M.B.M.; MARINHO, M.L.; GOMES, J.C.; SOUZA, L.F.S.; MAGALHÃES, A.F.J.; CARVALHO, O.S. Adubação nitrogenada no Nordeste. In: SIMPÓSIO SOBRE ADUBAÇÃO NITROGENADA NO BRASIL, 1., 1984, Ilhéus. Anais... Ilhéus: CEPLAC/SBCS, 1985. p.153-220.

SCHENCK, N.C.; PEREZ, Y. Manual for identification of VA mycorrhiza fungi. Gainesville: INVAM, 1987. $245 p$.

SIEVERDING, E. Vesicular-arbuscular mycorrhiza management in tropical agrosystems. Eschborn: GTZ, 1991.371p.

SIQUEIRA, J.O.; COLOZZI-FILHO, A.; OLIVEIRA, E. de. Ocorrência de micorrizas vesicular-arbusculares em agro e ecossistemas do Estado de Minas Gerais. Pesquisa Agropecuária Brasileira, Brasília, v.24, n.12, p.1499-1506, dez. 1989.

TARRAND, J.J.; KREIG, N.R.; DÖBEREINER, J. A taxonomic study of the Spirillum lipoferum group, with descriptions of a new genus, Azospirillum gen. nov., and two species Azospirillum lipoferum (Beijerinck) comb. nov. and Azospirillum brasilense sp. nov. Canadian Journal of Microbiology, Ottawa, v.24, p.967-980, 1978.

VINCENT, J.M. A practical manual for the study of root-nodule bacteria. Oxford: Blackwell Scientific Pub. Ltd., 1970. 164p. (International Biological Program Handbook, 15). 